\title{
PERBEDAAN RASIO C/N KOMPOS SAMPAH ORGANIK DAN DEDAUNAN SEGAR AKIBAT VARIASI LAMA WAKTU PEMBALIKAN DENGAN METODE RAK BOX DI TPS 3R ALDI LESTARI BANJARMASIN
}

C I N RATIO DIFFERENCES OF ORGANIC WASTE AND FRESH LEAVES DUE TO THE LENGTH OF REVERSAL TIME VARIATION WITH THE RACK BOX METHOD AT TPS $3 R$ ALDI LESTARI BANJARMASIN

\author{
Angelicha Fralisa Christiani, Andy Mizwar ${ }^{2}$, dan Rizqi Puteri Mahyudin ${ }^{3}$ \\ Jl. A. Yani Km. 36,5 Banjarbaru Kalimantan Selatan, 70714, Indonesia Program Studi Teknik \\ Lingkungan, Fakultas Teknik, Universitas Lambung Mangkurat \\ E-mail : angelichaa.fralisaaa@gmail.com
}

\begin{abstract}
ABSTRAK
Sampah masih menjadi permasalahan penting dalam pengelolaan sampah di Kota Banjarmasin. Untuk memecahkan permasalahan tersebut pemerintah mempunyai alternatif yang dapat melibatkan peran serta masyarakat serta meningkatkan upaya daur ulang sampah yaitu dengan adanya TPS 3R atau Tempat Pengelolaan Sampah (reuse, reduce, recycle) berbasis masyarakat. Salah satu upaya TPS 3R yaitu composting yang terdapat di TPS 3R Aldi Lestari. Metode composting yang digunakan yaitu open windrow rak box dimana metode ini merupakan metode baru dalam proses composting. Dalam penelitian ini dilakukan analisis tentang kualitas kompos dan rasio $\mathrm{C} / \mathrm{N}$ terhadap variasi lama waktu pembalikan 3 hari, 5 hari dan 7 hari dengan menggunakan bahan dasar sampah organik dan daun segar. Tumpukan akan dibangun sebanyak 6 tumpukan dengan ukuran panjang $110 \mathrm{~cm}$, lebar $30 \mathrm{~cm}$, tinggi $30 \mathrm{~cm}$ dan berat tumpukan 30 $\mathrm{kg}$. Analisis rasio $\mathrm{C} / \mathrm{N}$ dilakukan setiap 3 hari, 5 hari dan 7 hari sesuai jadwal pembalikan selama 30 hari. Hasil penelitian menunjukkan pada pengambilan sampel pertama masing-masing variasi telah menunjukkan Rasio C/N 19; 15,6; 16,2 yang berarti telah sesuai dengan SNI 19-7030-2004. Namun rasio $\mathrm{C} / \mathrm{N}$ tanah yang baik berkisar 10-12, sehingga yang memenuhi kategori ini ditunjukkan pada ditunjukkan pada hari ke-15 variasi pembalikan 3 hari yaitu 10,86, hari ke-15 variasi pembalikan 5 hari yaitu 12,93 dan hari ke-21 variasi pembalikan 7 hari yaitu 10,6.
\end{abstract}

Kata Kunci : composting, pembalikan, rak box

\begin{abstract}
Garbage is still an important problem in waste management in Banjarmasin City. To solve these problems the government has alternatives that can involve the participation of the community and increase waste recycling efforts, namely by the presence of a $3 R$ TPS or community-based reuse, reduce, recycle. One of the efforts of the $3 R$ polling station was composting found at the Aldi Lestari $3 R$ polling station. The composting method used is an open windrow rack box where this method is a new method in the composting process. In this study an analysis of the quality of compost and the ratio of $C / N$ to variations in length of reversal time of 3 days, 5 days and 7 days using the basic ingredients of organic waste and fresh leaves. The stack will be built as many as 6 piles with a length of $110 \mathrm{~cm}$, width of $30 \mathrm{~cm}$, height of $30 \mathrm{~cm}$ and a weight of $30 \mathrm{~kg}$.
\end{abstract}


Analysis of the $C / N$ ratio is carried out every 3 days, 5 days and 7 days according to the 30-day reversal schedule. The results showed that in the first sampling each variation had shown a $C / N$ 19 ratio; 15.6; 16.2 which means that it is in accordance with SNI 19-7030-2004. However, the good $C / N$ ratio ranges from 10-12, so that those who meet this category are shown in the 15th day of the 3-day reversal variation of 10.86, the 15th day of the 5-day reversal variation of 12.93 and 21 th day of the 7-day reversal of 10.6.

Keyword : Composting, reversal, rack box

\section{PENDAHULUAN}

Sebagai ibu kota Kalimantan Selatan, Banjarmasin merupakan kota terbesar dan terpadat sekaligus penyumbang terbesar sampah yang dihasilkan di Kalimantan (Huda, 2017). Untuk menyelesaikan permasalah sampah yang ada di Kota Banjarmasin pemerintah melakukan upaya yang melibatkan peran serta masyarakat serta meningkatkan upaya daur ulang sampah salah satunya adalah composting pada kawasan-kawasan tertentu, konsep ini dikenal dengan sebutan TPS 3R atau Tempat Pengelolaan Sampah (reduce, reuse, recycle) berbasis masyarakat (Sahwan, 2012). TPS 3R bertujuan untuk mengurangi sampah yang dibuang ke TPA, mengurangi pencemaran lingkungan serta mengubah perilaku masyarakat terhadap sampah (Radityaningrum dkk, 2017).

Dinas Lingkungan Hidup (DLH) Kota Banjarmasin menyatakan ada 11 (sebelas) TPS 3R yang dibangun di Kota Banjarmasin. Salah satunya TPS 3R Aldi Lestari yang terletak di Jalan Tembus Mantuil Komplek Aldi Persada Permai Kelurahan Mantuil Kecamatan Banjarmasin Selatan Kota Banjarmasin, Kalimantan Selatan. Area Layanan TPS 3R Aldi Lestari mencakup 2 RT yaitu RT 24 Kelurahan Mantuil dan RT 25 Kelurahan Alalak Utara dengan jumlah layanan sebanyak 215 kepala keluarga. Terdapat beberapa upaya dalam pengelolaan sampah di TPS 3R Aldi Lestari, yaitu pemilahan sampah, composting, budidaya tanaman, dan budidaya ikan . Composting di TPS 3R Aldi Lestari menggunakan bahan utama yaitu sampah organik sisa hasil dapur dan dedaunan yang diperoleh dari pelanggan TPS 3R Aldi Lestari (Ditjen Cipta Karya).

Pada Umumnya metode composting yang dilakukan TPS 3R di Kalimantan Selatan menggunakan metode open windrow bambu segitiga dimana metode ini merupakan metode sederhana untuk mendapatkan aerasi dan pencampuran hanya dengan membalikkan tumpukan kompos (Pudywardhana, 2006). Metode open windrow secara teknis tidak memerlukan sarana prasarana yang kompleks dan modern sehingga dapat diterapkan dengan mudah dan tepat guna. Demikian pula jumlah modal, biaya operasional dan biaya pemeliharaan tempat pengomposan relatif lebih rendah dibandingkan dengan sistem lain, sedangkan prosesnya sangat cocok dengan iklim tropis dimana kelembaban dan temperatur udara cukup tinggi dan stabil (Sinaga dkk, 2010). Kelemahan dari metode ini adalah proses aerasi dilakukan secara manual sehingga waktu pemrosesan cukup lama sekitar 5-8 minggu dan memerlukan lahan yang cukup luas (Dewi dkk, 2007).

Untuk menyempurnakan motode open windrow bambu segitiga yang ada di Kalimantan Selatan, maka pemerintah berupaya membuat sebuah metode open windrow yang lebih mudah, sederhana dan praktis. Metode tersebut dikenal dengan sebutan Rak Box dimana metode ini 
dapat dilakukan secara continue, proses pembalikan yang mudah, tempat penampung yang luas dan tidak memerlukan lahan yang luas serta proses composting yang cepat sekitar 15 hari untuk mendapatkan kompos siap pakai (Ditjen Cipta Karya). Seperti pada metode open windrow pada umumnya pembalikan dilakukan per 3 hari hari sekali untuk medapatkan aerasi yang cukup, untuk lebih mengefesiensikan proses pembalikan dilakukan percobaan pembalikan dengan rentang waktu 5 hari dan 7 hari. Namun belum ada pengukuran kelayakan kompos tersebut untuk diaplikasikan ke tanah atau tanaman, dikarenakan metode ini baru di TPS 3R. Oleh karena itu, dalam penelitian ini akan dilakukan pengukuran kualitas kompos.

\section{METODE PENELITIAN}

Bahan kompos yang digunakan yaitu sampai sayur, buah dan daun segar. Tumpukan dibangun menjadi 6 tumpukan dengan 2 pengulangan dan 3 perlakuan. Masing-masing tumpukan mempunyai ukuran panjang $110 \mathrm{~cm}$, lebar $30 \mathrm{~cm}$, tinggi $30 \mathrm{~cm}$ dan berat tumpukan $30 \mathrm{~kg}$. Penelitian ini dilakukan di lapangan menggunakan Rancangan Acak Lengkap (RAL) dengan perlakuan variasi lama waktu pembalikan 5 hari dan 7 hari. Sedangkan metode composting pada kontrol menggunakan lama pembalikan waktu 3 hari sekali.

Tabel 1. Analisis Sampel

\begin{tabular}{crccll}
\hline No & $\begin{array}{r}\text { Variabel } \\
\text { Analisa }\end{array}$ & Jenis Data & Satuan & \multicolumn{2}{c}{ Metode } \\
\hline 1 & C-Organik & Primer & $\%$ & \multicolumn{2}{c}{ Walkey and Black } \\
2 & N-Total & Primer & $\%$ & Kjeldahl & \\
3 & Suhu & Sekunder & ${ }^{\circ} \mathrm{C}$ & $\begin{array}{l}\text { Soil } \\
\text { Instrument }\end{array}$ & Survey \\
4 & pH & Sekunder & & Soil & Survey \\
5 & Kelembapan & Sekunder & Persentase (\%) & Moisture Meter \\
\hline
\end{tabular}

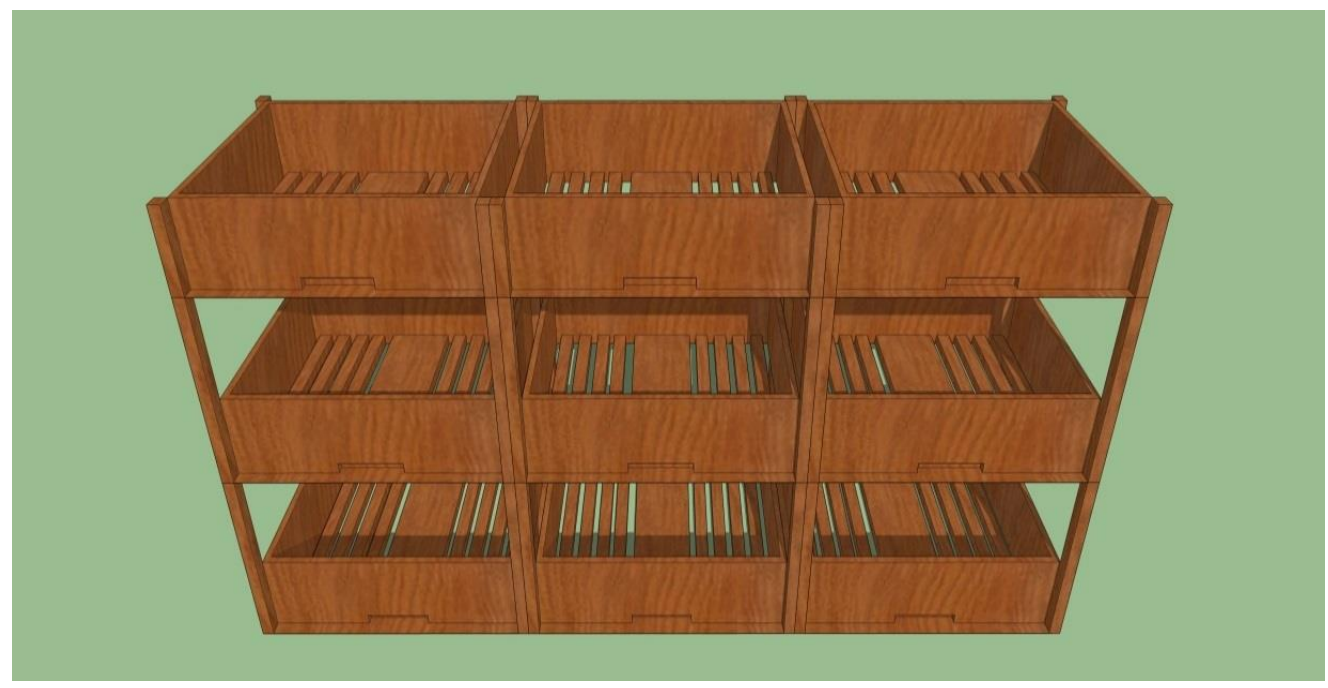

Gambar 1. Rangkaian Alat Rak Box 


\section{HASIL DAN PEMBAHASAN}

\section{A. Suhu}

Proses composting akan berjalan baik jika suhu pada proses composting sesuai untuk pertumbuhan mikroorganisme perombak. Berikut grafik perubahan suhu pada variasi lama waktu pembalikan 3 hari, 5 hari dan 7 hari.

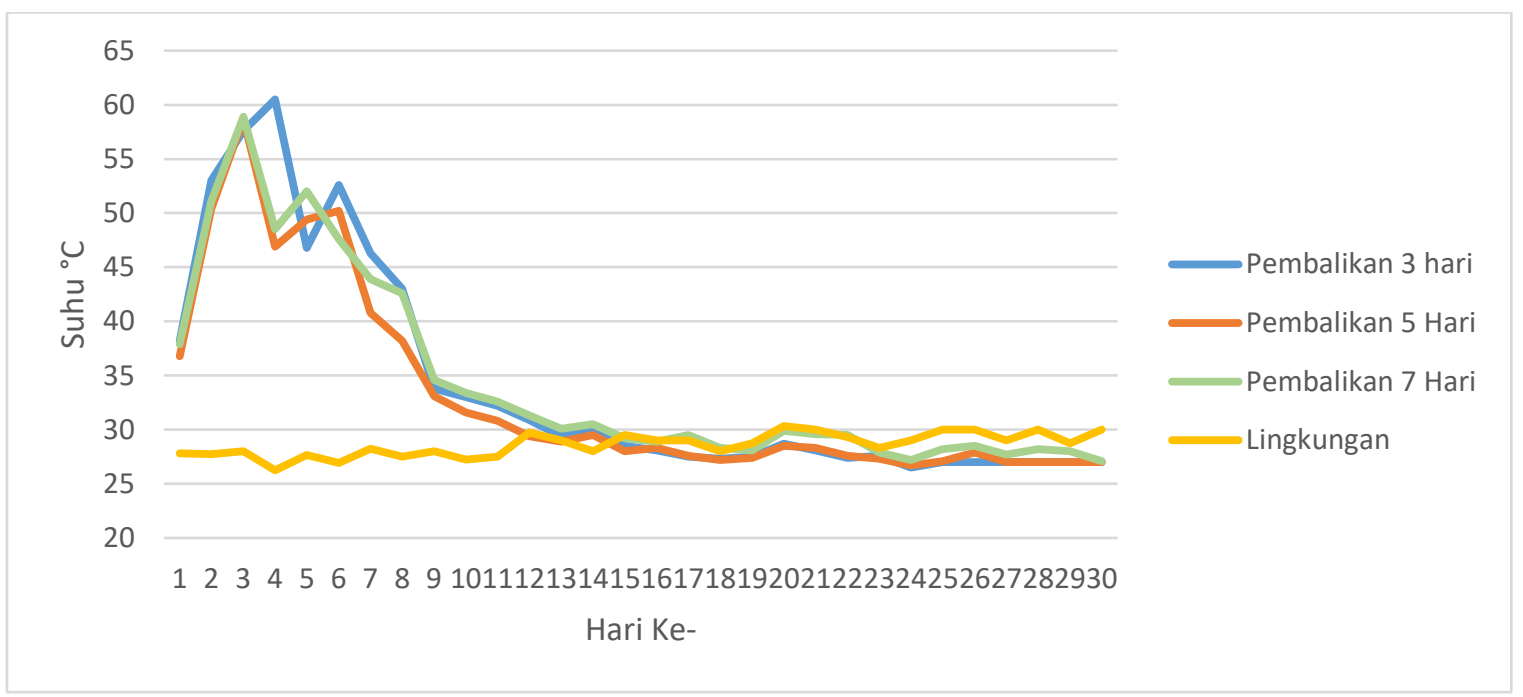

Gambar 2.Grafik Perubahan Suhu

Hasil pengamtan perubahan suhu pada gambar diatas menunjukkan proses composting dengan pembalikan 3 hari memiliki peningkatan suhu yang lebih tinggi dibandingkan dengan pembalikan 5 hari dan 7 hari. Suhu tertinggi pada pembalikan 3 hari yaitu $60,5^{\circ} \mathrm{C}$ terjadi pada hari ke-4 setelah pembalikan. Sedangkan pada pembalikan 5 hari dan 7 hari suhu tertinggi terjadi pada hari ke-3 yaitu $58,7^{\circ} \mathrm{C}$ dan $58,9^{\circ} \mathrm{C}$.

\section{B. $\mathbf{p H}$}

Derajat keasaman $(\mathrm{pH})$ merupakan salah satu faktor yang berperan dalam proses composting. Grafik perubahan $\mathrm{pH}$ kompos dengan perlakuan variasi lama waktu pembalikan 3 hari, 5 hari dan 7 hari dapat dilihat pada gambar berikut :

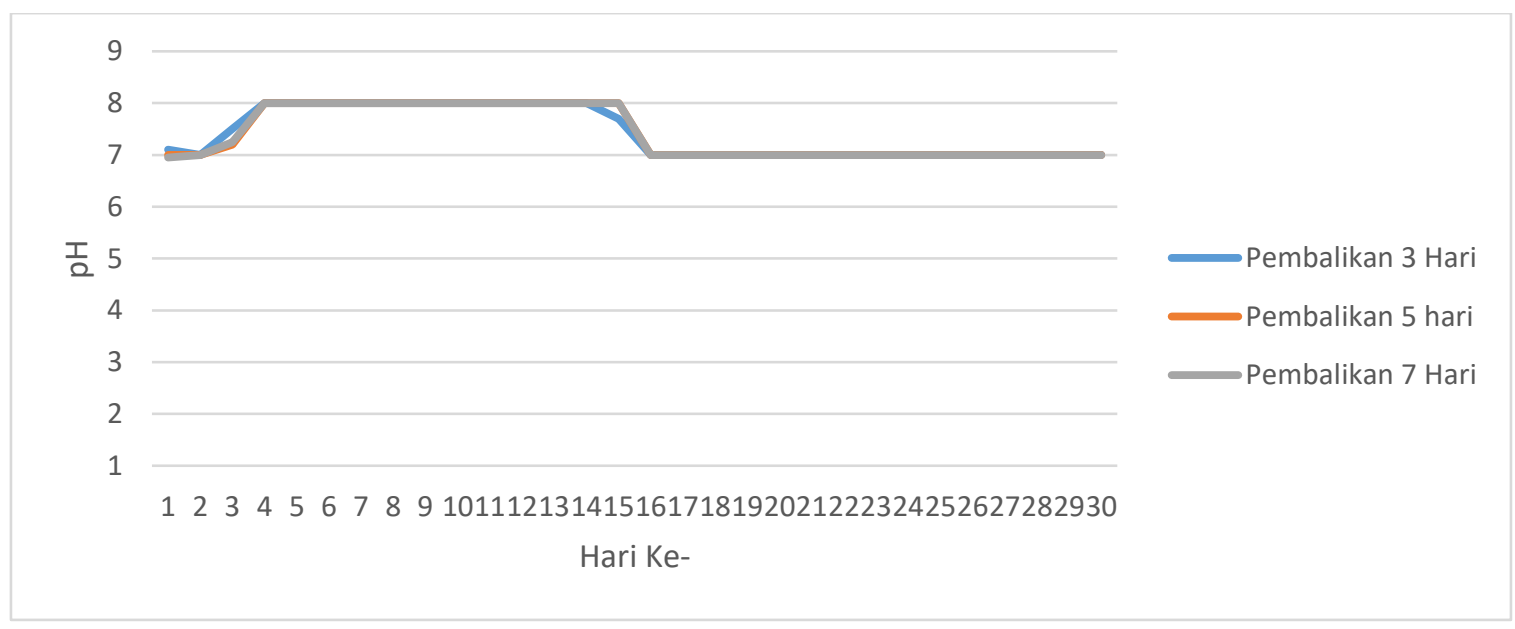

Gambar 3.Grafik Perubahan pH 
Nilai $\mathrm{pH}$ tercatat fluktuatif selama proses perubahan $\mathrm{pH}$ pada hari ke-1 hingga hari ke-3 disemua perlakuan menunjukkan nilai berkisar 6,95-7,5 kemudian terjadi kenaikan pH pada hari ke-4 hingga hari ke-18 yaitu 8 dan kembali turun pada hari ke-15 hingga hari ke-30 yaitu 7. Pada awalnya $\mathrm{pH}$ turun menunjukkan degradasi bahan organik menjadi asam organik. Kemudian $\mathrm{pH}$ berangsur-angsur naik hingga keadaan berubah menjadi sedikit basa dikarenakan asam-asam organik sederhana yang terbentuk pada dekomposisi awal dikonversi menjadi methan dan $\mathrm{CO}_{2}$ oleh bakteri pembentuk methan (Polpraset, 1993).

\section{Kadar Air}

Kadar air merupakan salah satu faktor yang mempengaruhi proses composting.. berikut grafik perubahan kadar air dengan variasi lama waktu pembalikan 3 hari, 5 hari dan 7 hari.

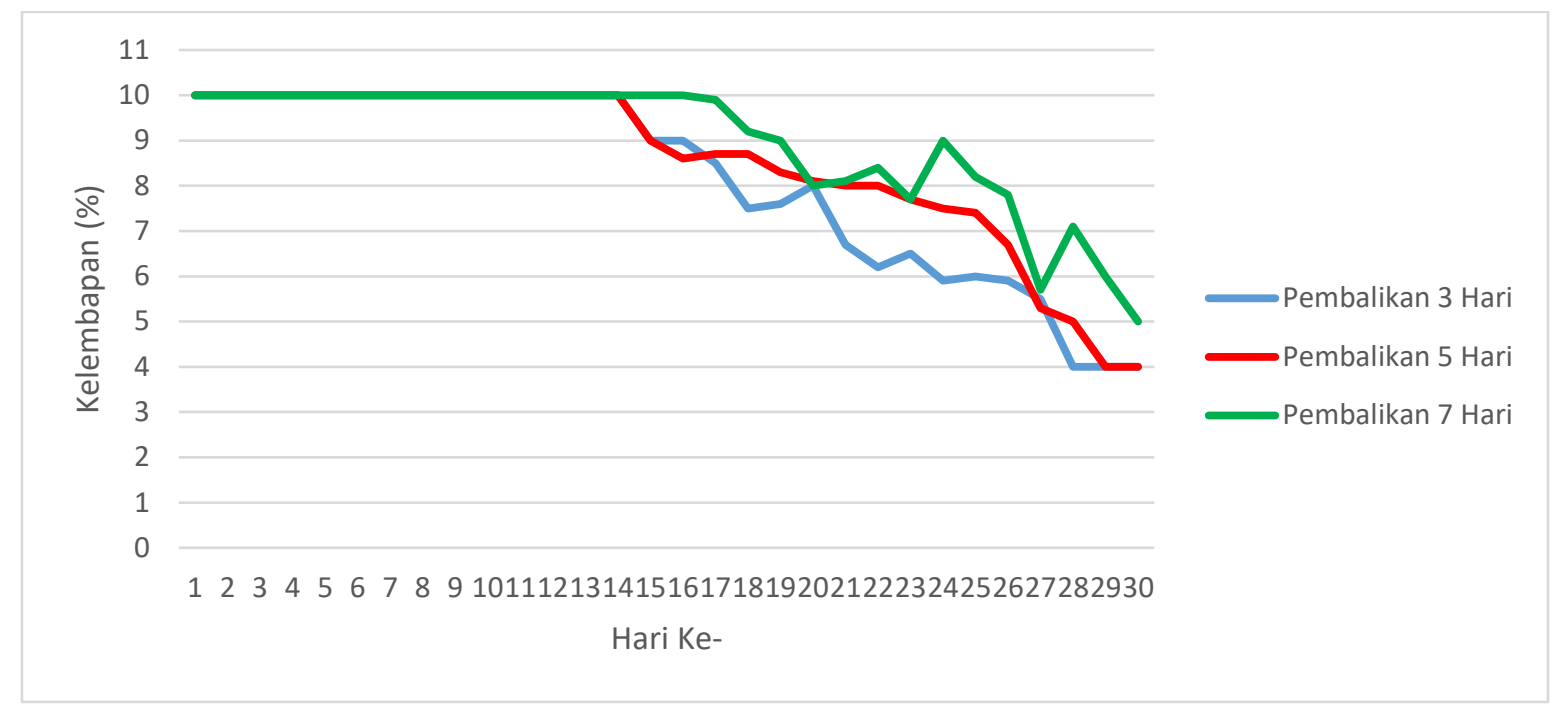

Gambar 4.Grafik Perubahan Kadar Air

Kadar air tercatat fluktuatif selama proses composting, pada hari ke-1 hingga hari ke-14 pada pembalikan 3 hari dan 5 hari kelembapan berkisar antara 100\% dan pada pembalikan 7 hari kelembapan 100\% mencapai hari ke-15. Kemudian berangsur-angsur turun hingga mencapai hari ke-30 berkisar antara 40-50\%. Kondisi ini masih sejalan dengan SNI 19-7030-2004.

\section{Rasio $\mathbf{C} / \mathbf{N}$}

Pengukuran nilai rasio $\mathrm{C} / \mathrm{N}$ pada penelitian ini dilakukan setiap 3 hari, 5 hari dan 7 hari selama 30 hari di laboratorium. Grafik rasio $\mathrm{C} / \mathrm{N}$ kompos dengan variasi lama waktu pembalikan 3 hari, 5 hari dan 7 hari dapat dilihat pada gambar berikut : 


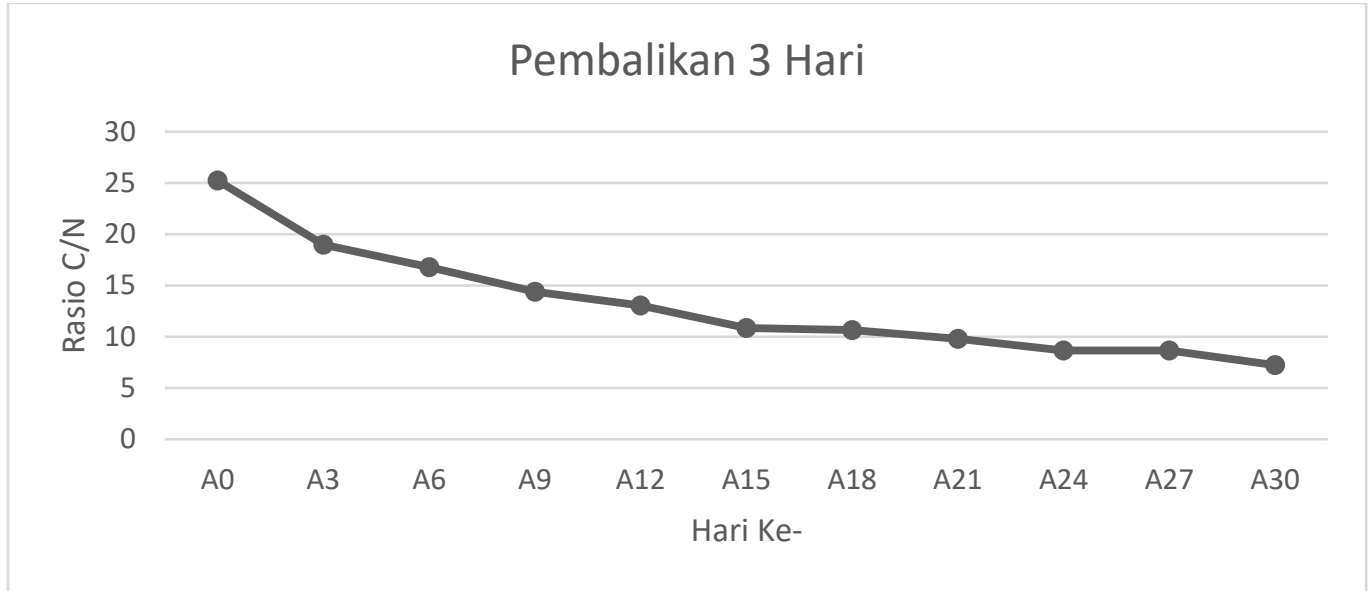

Gambar 5. Perubahan Rasio C/N pada lama waktu pembalikan 3 hari

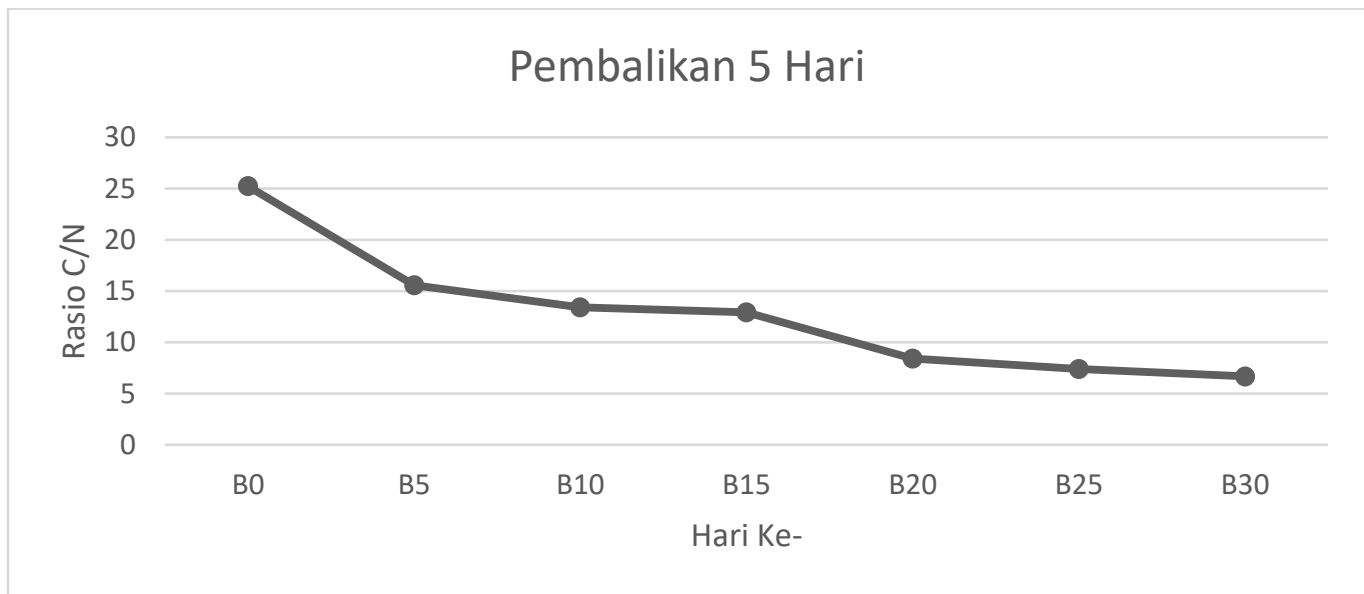

Gambar 6. Perubahan Rasio C/N pada lama waktu pembalikan 5 hari

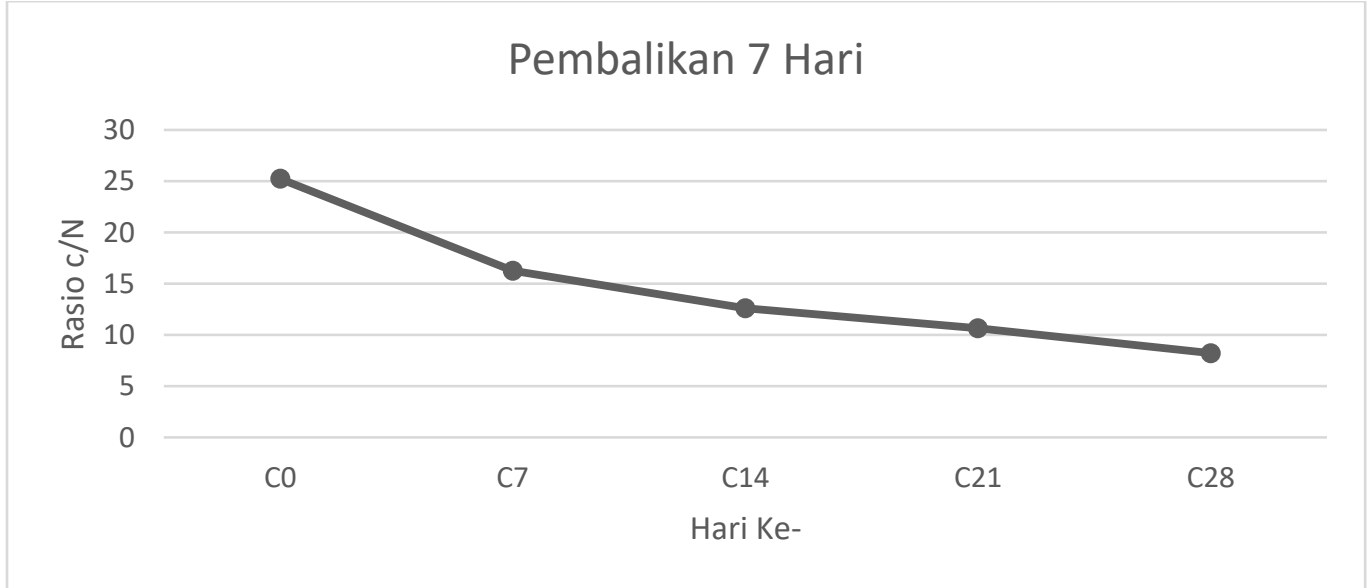

Gambar 7. Perubahan Rasio C/N pada lama waktu pembalikan 7 hari 
Tabel 2. Hasil Analisis Rasio C/N Setiap Pembalikan

\begin{tabular}{crcrcr}
\hline Hari & $\begin{array}{c}\text { Rasio C/N } \\
\text { pembalikan 3 } \\
\text { hari }\end{array}$ & Hari & $\begin{array}{c}\text { Rasio C/N } \\
\text { pembalikan } \\
\text { 5 hari }\end{array}$ & Hari & $\begin{array}{c}\text { Rasio C/N } \\
\text { pembalikan } \\
\text { 7 hari }\end{array}$ \\
\hline A0 & 25,23 & B0 & 25,23 & C7 & 25,23 \\
A3 & 19 & B5 & 15,565 & C14 & 16,275 \\
A6 & 16,775 & B10 & 13,42 & C21 & 12,61 \\
A9 & 14,375 & B15 & 12,93 & C28 & 10,665 \\
A12 & 13,055 & B20 & 8,415 & & \\
A15 & 10,86 & B25 & 7,405 & & \\
A18 & 10,64 & B30 & 6,685 & & \\
A21 & 9,79 & & & & \\
A24 & 8,65 & & & & \\
A27 & 8,645 & & & & \\
A30 & 7,23 & & & & \\
\hline
\end{tabular}

Berdasarkan gambar diatas terhadap variasi pembalikan selama 3 hari, 5 hari dan 7 hari sekali (A, B dan C) dapat dilihat bahwa kompos yang dihasilkan dari hari ke-1 hingga hari ke-30 memiliki rasio $\mathrm{C} / \mathrm{N}$ yang terus menurun. Pada variasi pembalikan $\mathrm{A}$ hari ke-3 rasio $\mathrm{C} / \mathrm{N}$ menunjukkan nilai 19 , kemudian pada variasi pembalikan $\mathrm{B}$ hari ke-5 rasio $\mathrm{C} / \mathrm{N}$ menunjukkan nilai 15,6 dan variasi pembalikan $C$ hari ke-7 menunjukkan nilai 16,2 . Nilai-nilai tersebut sudah memenuhi standar kompos yang terdapat pada SNI : 19-7030-2004 yaitu berkisar antara 10-20. Namun menurut (Indriani, 2006) Rasio $\mathrm{C} / \mathrm{N}$ tanah berkisar antara 10-12. Dalam penelitian ini Rasio C/N yang mendekati rasio C/N tanah ditunjukkan pada hari ke-15 variasi A yaitu 10,86, hari ke-15 variasi B yaitu 12,93 dan hari ke-21 variasi C yaitu 10,6.

\section{KESIMPULAN DAN SARAN}

\section{A. Kesimpulan}

Hasil analisa rasio $\mathrm{C} / \mathrm{N}$ variasi lama waku pembalikan 3 hari memiliki rasio $\mathrm{C} / \mathrm{N}$ yang sesuai berdasarkan rasio $\mathrm{C} / \mathrm{N}$ tanah yaitu sebesar 10,86 pada hari ke-15. Namun, berdasarkan uji statistika tidak ada perbedaan antara rasio $\mathrm{C} / \mathrm{N}$ akibat variasi lama waktu pembalikan.

\section{B. Saran}

Penelitian dapat dikaji lebih dalam lagi dan dapat dilakukan penelitian mengenai variasi komposisi bahan yang digunakan,

\section{DAFTAR PUSTAKA}

Dewi, C. M., Mirasari, D. M., Antaresti, \& Wenny Irawati. (2007). Pembuatan Kompos Secara Aerob Dengan Bulking Agent. Widya Teknik, 6(1), 21-31.

Direktorat Jenderal Cipta Karya. (2017). Penyehatan Lingkungan dan Permukiman

Huda, Nurholis. 2017. Sampah Kiat Merepotkan di Kalsel TPS 3R Pun Jadi Tumpuan. Tribunbanjarmasin.com. 9 Maret 2017.

Pudywardhana, C. (2006). Pengelolaan Sampah Menjadi Kompos Skala Kawasan Dengan 
Menggunakan Metode Open Windrow Bergulir (Studi Kasus Pengolahan Sampah di Perumahan Griya Satria Bantarsoka Purwokerto). Teodolita, 7(2), 17-23.

Radityaningrum, A. D., Caroline, J., \& Restianti, K. (2017). Potensi Reduce , Reuse , Recycle ( 3R ) Sampah Pada Bank Sampah `Bank Junk for Surabaya Clean ( Bjsc ) `. Jukung Jurnal Teknik Lingkungan, 3(1), 1-11.

Sahwan, F. L. (2012). Analisis Proses Komposting Pada Pengelolaan Sampah Berbasis Masyarakat Skala Kawasan (Studi Kasus Di Kota Depok). Teknik Lingkungan, 13(3), 253260.

Sinaga, A., Sutrisno, E., \& Budisulistiorini, H. (2010). Perencanaan Pengomposan Sebagai Alternatif Pengolahan sampah organik (studi Kasus: TPA Putri Cempo - Mojosongo). Jurnal PRESIPITASI, 7(1), 13-22. 